\title{
Vieux-Colombier Uma Luz Para o Teatro Brasileiro ${ }^{1}$
}

Ivo Godois e Vera Collaço (Orientadora) ${ }^{2}$

Palavras Chaves: Iluminação Cênica, Luiz Jouvet, Teatro brasileiro.

Resumo: O Vieux-Colombie foi uma proposta inovadora tanto no espaço cênico como para a formação do ator. Iniciado pelo Francês Jacques Copeau em 1913, teve em seu aluno, Louiz Jouvet um de seus grandes disseminadores. Este também praticou experimentos com iluminação cênica. Como diretor passou pelo Brasil demonstrando espetáculos que continham qualidades também na iluminação, o que pode ter provocado interferência na montagem da peça Vestido de Noive realizada pelo grupo carioca Os Comediantes.

O teatro do Vieux-Colombier (Velho Pombal) iniciou suas atividades na Paris dos anos de 1913, situado à margem esquerda do Rio Sena, vizinho dos estabelecimentos escolares e universitários, próximo de um bairro rico. Jacques Copeau instalou-se num espaço sem as características extremamente adequadas à representação artística. Precisou adaptá-lo e proceder à concretização de um espaço em consonância com a renovação dramática a que almejava.

Copeau não inovou na proposta de criação desse espaço, mas conseguiu consolidar um projeto meditado por muito tempo, e a partir do período em que se manteve ativo deixou sua referência para os experimentos futuros. Antes de sua reformulação espacial interna, o "Velho Pombal" já havia sido ocupado por representações artísticas, quando ainda com o nome de Athénée Saint-Germain. Desta vez, porém, alem da mudança do nome, no espaço instalavam-se artistas cuja concordância intelectual e gosto comum da ação os tornariam companheiros de luta, com o intuito de estabelecerem um ideal para a formação do ator e para a atuação em equipe. Talvez querendo distanciar-se do culto desenfreado do estrelismo, como afirma Roubine (1998, p. 52) Copeau procurava "erguer um teatro novo sobre alicerces intactos, e limpar o palco de tudo quanto o suja e oprime”. Para Copeau o espaço novo deveria ser diferente dos teatros com arquitetura à italiana construídos no século XIX e que continuavam sendo implantados no início do XX bem próximo dele, nas edificações do Théâtre des ChampsElysées (1911) e da Comédie des Champs-Elysées (1913). Jacques Copeau consolidou propostas que já haviam sido levantadas nas décadas anteriores, pois em 1890 o também francês André Antoine denunciava a irracionalidade do espetáculo no espaço à italiana,

${ }^{1}$ PPGT CEART/UDESC - Projeto de Mestrado: A Iluminação de Um Palco. Orientadora Vera Martins Collaço.

${ }^{2}$ Ivo Godois - Acadêmico do Programa de Pós Graduação em Teatro do Centro de Artes da UDESC, Vera 
Martins Collaço é Professora Dr do Departamento de Artes Cênica do CEART - UDESC

DAPesquisa, Florianópolis, v.3 n.5, p.1000-1009, 2008. 
expondo assim os primeiros fragmentos críticos sobre a soberania desse tipo de sala de representação.

Ao ser implantado, o teatro do Vieux-Colombier não chegou a transformar a relação público-espetáculo, pois manteve a frontalidade. Já não apresentava, porém, o palco separado da sala. Uma escada gerava uma espécie de complemento de comunicação, um vínculo entre ambas e trazia na iluminação a ligação da cena ao espectador. De fato, "a exemplo de Craig, a quem admira profundamente, Copeau utiliza uma iluminação modulável, cuja fonte se situa atrás do público, evitando assim o efeito de separação entre o espectador e a caixa do palco que o uso da ribalta costuma suscitar" (Roubine, 1998, p. 86). Copeau também tinha conhecimento de outros projetos arquitetônicos e práticas de iluminação em espaços experimentais através de Adolphe Appia, com o qual mantinha proximidade. Em um encontro ${ }^{3}$, Adolphe Appia, expressou-lhe o fascínio que o exercera o projeto de Emile-Jaques Dalcroze, desenvolvido em Hellerau, e os experimentos feitos por este e por Appia no espetáculo Orphée (Orfeu).

Jaques-Dalcroze mandou construir, em Hellerau, nos arredores de Dresde, na Suíça, um teatro concebido como um vasto ateliê pelo arquiteto $\mathrm{H}$. Tessenow. Dalcroze instalou na localidade sua Escola de Formação para a Música e para o Ritmo. Desde 1898, Appia havia feito para Dalcroze projetos de disposição de um espaço com diferentes planos. Alexander Salzmann fez a adaptação do espaço de representação em 1911, inspirado nos projetos de Appia (para o espetáculo Orphée (Orfeu) montado já em Genebra e não mais em Hellerau, da qual Dalcroze havia se mudado. Salzmann acrescentou à adaptação um sistema de iluminação aperfeiçoado para aquele espaço. Claudel entusiasmou-se ao assistir o espetáculo e escreveu artigo na Nova Revista Francesa em 1913, da qual Copeau era diretor. Detalhou a sala onde foi representado o espetáculo Orfeu como um vasto retângulo onde não havia cenários fixos. Os elementos cênicos se moviam e se encaixavam uns aos outros. Nas paredes e no teto havia tecidos brancos esticados e, atrás destes, gambiarras com lâmpadas elétricas em uma disposição retangular. A localização desses elementos luminosos não deixava visíveis os focos de luz. Claudel também descreveu em seu artigo a existência ao fundo da sala de uma mesa de luz, a qual permitia que uma só pessoa, ao acompanhar o espetáculo, operasse a distribuição luminosa que lhe parecesse necessária às cenas.

Com a criação da escola e seu sistema de repertório e alternância de espetáculos em cada temporada, Copeau permanece como o primeiro a concretizar a reforma do ensino do ator e a abrir caminho para outros, nesse campo. Longe de ser contra a iluminação cênica, Copeau

\footnotetext{
${ }^{3}$ COPEAU, Jacques. A Improvisação In Registros III , Registros do Vieux-Colombier. Tradução de José Ronaldo Faleiro
}

DAPesquisa, Florianópolis, v.3 n.5, p.1000-1009, 2008. 
apenas não concordava com o rumo de algumas pesquisas que se distanciavam das suas tentativas de esvaziar o palco. Podemos perceber esse conhecimento na área da luz em afirmações contidas no texto "O Teatro do Vieux Colombier" ${ }^{4}$.

\begin{abstract}
Não que sejamos insensíveis à arte de criar uma atmosfera por meio da cor, da forma e da luz. Aplaudimos, há três anos, a feliz iniciativa do Sr. Jacques Rouché, que se esforçava, com o concurso de excelentes pintores, para dotar o cenário de uma nova qualidade estética. Conhecemos as pesquisas, acompanhamos os projetos e as realizações dos Srs. Meyerhold, Stanislavski, Dântchenko na Rússia; dos Srs. MaxReinhardt, Littmann, Fuchs e Erler na Alemanha; dos Srs. Gordon Craig e Granville Barker na Inglaterra.
\end{abstract}

Copeau concentrava esforços na encenação voltada ao trabalho de interpretação, e negava a importância de toda e qualquer maquinaria. Acreditava que apaixonar-se por invenções de engenheiros ou de eletricistas seria conceder uma importância maior aos elementos cênicos e à disposição das luzes, o que levaria a cair nos truques. Dentre seus vários alunos e seguidores de pesquisa, fechemos aqui o foco sobre, Louis Jouvet, que em sua jornada como diretor e ator procedeu influências marcante também no Brasil.

A iluminação em seus excessos foi um elemento combatido por Copeau, Talvez a busca desse diretor tenha gerado em Jouvet a necessidade de experimentar equipamentos de luz e até construí-los. O conhecimento sobre práticas luminosas vinha do contato de seu mestre com grandes pensadores e homens de teatro da época. Entre 1913 e 1914, Jouvet atuou como ator em 13 (treze) espetáculos. Com a guerra, tanto ele como seu diretor foram recrutados para o fronte e o teatro foi fechado. Copeau foi dispensado meses depois, o que não ocorreu com seu aluno. Os contatos mantiveram-se através de correspondência e a busca para inovar a representação cênica também. Copeau foi nomeado para uma missão cultural nos Estados Unidos, e através de comunicações escritas com Jouvet desenvolveram um dispositivo cênico, espécie de tablado, com pequenas diferenças de elevação que permitiam obter diferentes espaços cênicos em um único lugar. A materialização do experimento, já com a presença de Jouvet liberado da obrigação militar, ocorreu em novembro de 1917, no Garrick Theatre o Vieux Colombier que Copeau montou em Nova Iorque, e onde trabalhou durante dois anos na capital norte americana. Jouvet, quando no fronte, além de projetar o tablado cênico, desenvolvia leituras e experimentos também com finalidades de construir dispositivos luminosos, como se nota nos comentários contidos nesta carta dirigida a Copeau:

Encontrei um dispositivo para suprimir de certa maneira as frisas - e para adotar as luzes fixas em lugar das gambiarras - Luzes móveis em todas as posições e inclinações. Estou

\footnotetext{
${ }^{4}$ COPEAU, Jacques. O Teatro do Vieux Colombier. Tradução de José Ronaldo Faleiro
} 
muito contente com isso. Creio que poderá funcionar, embora eu não veja o efeito produzido. 5

Esse anteparo luminoso teve aperfeiçoamento após o fim da guerra. Jouvet patenteou a invenção e experimentou-a em fevereiro de 1920, quando da reabertura do Vieux Colombier em Paris. Naquele período também se instalou no espaço a escola para formação de atores com cursos teóricos e práticos, na qual Jouvet ficou responsável por ministrar conhecimentos sobre arquitetura teatral. Copeau instalou no espaço reinaugurado, ateliês de eletricidade e carpintaria cuja direção delegou a Jouvet, para que este procedesse a pesquisas. Juntos trabalharam para transformar o palco do Vieux-Colombier com o propósito de instalar ali o dispositivo arquitetônico fixo já experimentado em Nova Iorque. Na mudança nada restou da caixa de cena do antigo Vieux-Colombier. Eles eliminaram a boca de cena e acrescentaram uma escada com a finalidade de deixar maior proximidade entre a cena e o público. Receberam criticas pela ousadia, pois a acústica do espaço adaptado não foi favorecida, devido ao material (cimento) utilizado para cobrir o chão.

Os rumos individuais de Jouvet esclareceram-se em 1922, quando aceitou o posto de diretor técnico das duas salas da Comédie des Champs-Elysées. Em 1924, Copeau anunciou o fechamento do Vieux-Colombier, alugou um castelo na Borgonha, no interior da França, e transmitiu em setembro daquele ano a companhia do Vieux-Colombier a Jouvet. Copeau mudou-se então para o castelo acompanhado de trinta e três pessoas, a fim de dedicarem-se exclusivamente à escola de atores e às pesquisas. Com dificuldades financeiras, viu-se obrigado a abandonar seus objetivos em fevereiro de 1925. Alguns alunos, mesmo assim, permaneceram ao lado dele entre 1925 e 1929, sendo chamados pelos habitantes da região de Copiaus. Em 1929 Copeau resolveu dissolver o grupo e prosseguir seus projetos de forma individual.

Por sua vez, Jouvet continuava a sua jornada pessoal como ator e diretor, integrando-se com antigos companheiros do Vieux-Colombier e com outros mais que a cena teatral francesa gerava. No decorrer da década de 30, além de incursões na área do cinema, Jouvet trabalhou no Théâtre de l'Athénée [Teatro do Ateneu], onde estabeleceu e manteve uma sólida amizade e parceria com o escritor Jean Giraudoux e com o cenógrafo Christian Bérard. Pôde então aperfeiçoar ainda mais seus conhecimentos do texto dramático e da cenografia. Encenou junto a estes alguns de seus maiores sucessos.

Em 1936, os integrantes do "Cartel”, fundado em 1927 para defender interesses individuais de um grupo de diretores, encontrar-se-iam para uma missão importante na renovação dos clássicos da dramaturgia teatral francesa. Com a nomeação de Edouard Bourdet

${ }^{5}$ COPEAU, Jacques. A Improvisação. Tradução de José Ronaldo Faleiro. 
para o cargo de administrador da Comédie-Francaise, este abre um precedente na história dessa instituição e convida para dirigirem espetáculos Jouvet, Gaston Baty, Charles Dullin e Jacques Copeau. Suas funções não implicavam no abandono do cargo de diretores em seus teatros respectivos. Devido a problemas graves de saúde, Bourdet afastou-se da administração da Comédie-Francaise em 1939. No mesmo ano Paris foi ocupada pelos alemães, o que gerou implicações diretas na administração e no repertório da instituição, que até então só permitia a encenação de dramaturgos franceses. Em 1940 o diretor licenciado foi demitido, assumindo o cargo o seu interino Jacques Copeau. Este fora nomeado numa situação conturbada e não contava que seus companheiros manifestassem apoio a Boudet - entre eles Jouvet, que discordava da encenação de dramaturgos alemães pela Comédie-Française. Nesse contexto, Copeau pediu demissão em março de 1941, tendo-se mantido por apenas dez meses no cargo.

Por não concordar com o programa cultural estabelecido pelos alemães Jouvet resolveu deixar Paris, junto com sua companhia para Portugal e em seguida para a América do Sul, aportando no Rio de Janeiro e outras metrópoles Sul-Americana. O Brasil apresentava um terreno fértil para o desenvolvimento da arte, na época. O governo Vargas através do seu Ministro da Educação e saúde Gustavo Capanema e seu fiel assistente Carlos Drummond de Andrade buscavam consolidar a modernidade dentro do Estado Novo Getulista. O idioma francês era um dos mais utilizados por intelectuais das academias e por vários artistas brasileiros que visitavam com frequiência aquele país.

Ao final de junho de 1941, Jouvet chega ao Rio, seguido de vinte e cinco pessoas entre atores e técnicos. 34 (trinta e quatro) toneladas de materiais acompanhavam a trupe. Todo esse volume de objetos e de pessoas não visava a atender a um único espetáculo. Jouvet viera nesta turnê, inicialmente programada para ter a duração de três meses, com várias obras em seu repertório. Ao longo do mês de julho foram mostradas sete peças diferentes de dramaturgos diversos, com a habilidade de interpretação da mesma equipe, que se apresentava dia sim, dia não. Nota-se por aí a importância dada pelo diretor em ter a presença de sua equipe técnica acompanhando a turnê com a destreza necessária para reestruturar cenário e iluminação de um dia para o outro. É de se ressalta que essa prática deve ter gerado aprendizado aos técnicos brasileiros que os auxiliaram nas duas temporadas no Rio de Janeiro e São Paulo, em 1941 e 1942.

Jouvet tinha 54 anos quando chegou ao Brasil. Já era um ator de renome e um diretor reconhecido pela sua qualidade profissional. Sobre os cuidados e dedicação que tinha com seus trabalhos encontramos referências no depoimento de Álvaro Moreyra, ligado ao teatro amador carioca, em 1941, ao narrar sua conversa com o diretor na primeira temporada. Relatou então a 
ele que assistira à estréia de Jouvet na inauguração do Vieux-Colombier, em 1913: “... prolongar a conversa - nas palavras de Moreyra - seria bom, se ele não fosse um homem

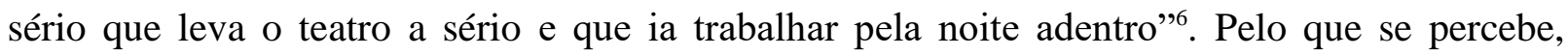
Jouvet e sua equipe técnica trabalhavam intensamente para instalar e readequar cenário e iluminação dos espetáculos, no pouco tempo que restava entre uma apresentação e outra. Décio de Almeida Prado que também já havia assistido a trabalhos de Jouvet em 1939, quando estivera em Paris, e que em 1941 iniciava sua carreira como critico literário, apontou detalhes, em sua crítica na revista Clima $n^{\circ} 3$, que enalteciam a qualidade dos trabalhos deste diretor, incluindo as virtudes da iluminação. Décio salientava o valor de "um grupo de peças estrangeiras encenadas da mesma forma como foram criadas, pela mesma companhia, com o mesmo cenário, os mesmos efeitos de luz" ". Sobre o impacto causado pelas duas temporadas de Jouvet no teatro brasileiro, é oportuno lembrar o depoimento de Gustavo Dória, um dos integrantes do grupo carioca Os Comediantes, que iniciava suas atividades no mesmo período. Após assistir aos espetáculos de Jouvet, o grupo reavaliou suas propostas de teatro:

...Todos conhecíamos a importância de Jouvet, sua posição no teatro francês, sua descendência direta do movimento de Copeau. Mas jamais poderíamos imaginar que o espetáculo teatral pudesse atingir aquele grau de elaboração artística. Jamais tínhamos visto uma conjunção tão perfeita entre texto, interpretação e montagem ${ }^{8}$.

O caráter novo e o aspecto moderno que o grupo procurava estavam em frente deles. Com sua história e qualidade de trabalho, o ilustre diretor francês passou a ser figura comentada nos meios artísticos e intelectuais. No Rio de Janeiro o contato com os espetáculos de Jouvet foi além do visual, pois, a convocação de um grupo de pintores e desenhistas para trabalharem com ele quando da segunda temporada carioca em 1942, permitindo que os artistas locais convivessem com a obra deste diretor. Não se tem aqui um registro do conteúdo transmitido aos colaboradores brasileiros, mas Jouvet não deixaria passar a oportunidade de expor as vantagens do cenário no formato de praticáveis e diferentes níveis que nos tempos do Vieux-Colombier fora criado. Embora não seja citado como um dos integrantes da equipe que auxiliou Jouvet, o cenógrafo Thomas Santa Rosa estava imerso no meio político e artístico da época. Não ficaria distante das rodas de intelectuais ligados ao Governo ou imune a comentários sobre inovações cenográficas aprendidas pelos membros da equipe colaboradora de Jouvet. O cenário da peça Vestido de Noiva foi produzido de forma criativa e inovadora,

\footnotetext{
${ }^{6}$ Pontes, Heloisa. Louis Jouvet e o nascimento da crítica e do teatro brasileiro moderno.

${ }^{7}$ PONTES, Heloisa. Louis Jouvet e o nascimento da crítica e do teatro brasileiro moderno.

${ }^{8}$ Idem.
} 
estando assim dentro do que Jouvet considerava potencialidade do artista brasileiro. A construção de madeira estabelecia dois andares e, juntamente com o nível do palco, favorecia os três planos narrativos solicitados pelo dramaturgo. A criatividade de Santa Rosa estava na existência de arcos que facilitavam a entrada e saída dos atores, e também na projeção de efeitos de luz que contagiavam o público. Esses arcos remetiam aos Arcos da Lapa, um ponto característico carioca que contextualizava o espetáculo em determinada região. Nelson Rodrigues escreveu o texto em 1943, após as duas temporadas realizadas por Jouvet no Rio de Janeiro, em 1941 e 1942. Não se tem registros de que o autor tivesse assistido ao espetáculo de Jouvet ou de que conhecesse as pesquisa de Copeau com os "praticáveis" que proporcionavam diferentes planos sem precisar mudar de cenário durante a apresentação. No período em que o diretor francês esteve no Rio, Nelson era jornalista de conceituados periódicos da capital nacional. Ingressara havia pouco tempo na dramaturgia, e a divulgação de notícias do renomado diretor que valorizava a criação do texto circulando pela cidade e recebendo artistas amadores em seu apartamento não deveria tê-lo passado despercebido. Os membros do grupo Os Comediantes entenderam a importância inovadora de Jouvet e intensificaram relações:

Generoso com os atores amadores, Jouvet os recebia em seu apartamento, durante os sete meses em que residiu no Rio de Janeiro. Brutus Pedreira e outros integrantes de $\underline{\mathrm{Os}}$ Comediantes voltaram de uma dessas visitas - relembra Gustavo Dória - com a "verdade estarrecedora: qualquer iniciativa que pretendesse fixar no Brasil um teatro de qualidade, um teatro que atingisse verdadeiramente a uma platéia, não estaria realizando nada enquanto não prestigiasse a literatura nacional! (....) O ponto de partida era o autor brasileiro". (Ibidem)

Nelson Rodrigues mantinha proximidade com o ministério Capanema: Manuel Bandeira que trabalhava neste ministério foi o primeiro a receber cópia da peça Vestido de Noiva. Escreveu manifestando elogios ao texto. Apesar dos bons comentários da imprensa, o autor não conseguia levá-la para a cena. Alegavam-se dificuldades para a construção do cenário e os custos elevados de sua confecção e implantação. Surgiu então Thomas Santa Rosa, que achou possível a sua realização e falou com o polonês Zbigniew Ziembinski. Os dois Juntaram-se então com a procura objetivada pelo Grupo Os Comediantes e decidiram-se pela montagem do texto, que estreou após oito meses de exaustivos ensaios. O plano de luz para a estréia da obra continha 132 efeitos. Foi idealizado por Ziembinski e acompanhado de perto por Santa Rosa. Com os técnicos que já haviam auxiliado a equipe de Jouvet, no Teatro Municipal do Rio, foi que Ziembinski inovou a iluminação cênica brasileira. Dedicou muitas horas à montagem de luz, trabalhando noite adentro para proceder a melhorias, e aperfeiçoá-la. Tem-se aí outra semelhança com a proposta de Jouvet, que assim agiu para não perder qualidade, no curto tempo de readequação em suas peças. A importância dada ao posicionamento dos 
equipamentos de luz para gerar bons efeitos e a dedicação de tempo para tal fim torna o espetáculo Vestido de Noiva, de 1943, como um divisor de águas no Brasil, no tocante à valorização da ferramenta geradora de luminosidade na cena e à dos profissionais que a executam. Sobre a iluminação da peça na estréia, o escritor Nelson Rodrigues assim escreveu :

\footnotetext{
Não posso falar da luz sem lhe acrescentar um ponto de exclamação. Em 1943, nosso teatro não era iluminado artisticamente. Pendurava-se, no palco, uma lâmpada de sala de visitas, ou de jantar. Só. E a luz fixa imutável - e burríssima - nada tinha a ver com os textos e os sonhos da carne e da alma. Ziembiski era o primeiro, entre nós, a iluminar poeticamente e dramaticamente uma peça. Estou vendo Alaíde, ao aparecer, pela primeira vez, de noiva. Ficamos atônitos de beleza. Dentro da luz, era um maravilhoso e diáfano pavão branco?
}

Nelson Rodrigues não deixa pistas claras sobre uma possível influência recebida de outros espetáculos. Observe-se, porem, a frase que se refere a condição da luz cênica no teatro brasileiro de então: "nosso teatro não era iluminado artisticamente". Na seqüência, o teatrólogo reforça a sua afirmativa: "Ziembinski era o primeiro entre nós..." Por aí podemos entender que ele conhecia trabalhos de qualidade executados por diretores de outros países. Entre estes, poderiam ser incluídos os trabalhos de Jouvet em suas duas temporadas no Rio de Janeiro em períodos anteriores à criação do texto de Nelson Rodrigues, da direção de Ziembinski, da cenografia de Santa Rosa e da montagem do Grupo Os Comediantes. Estes últimos assumiram, em depoimento já aqui transcrito, a decisiva influência do diretor francês para os rumos seguidos pela equipe.

Portanto a suposição esta lançada: teria a presença de Louiz Jouvet e sua companhia, em temporada no Brasil no início dos anos de 1940, influenciado direta ou indiretamente a primeira montagem de Vestido de Noiva?.

Bibliografia:

${ }^{9}$ MOSTAÇO, Edélcio. Aspectos da iluminação.

DAPesquisa, Florianópolis, v.3 n.5, p.1000-1009, 2008. 
CARLSON, Marvin. Teorias do Teatro. Tradução de Gilsom César Cardoso de Souza. São Paulo: UNESP, 1997.

COPEAU, Jacques. A Improvisação, in Registros III. Os Registros do Vieux Colombier (Velho Pombal). Textos coletados e estabelecidos por Marie-Hélène Dasté e Suzanne Maistre SaintDenis. Paris: Gallimard, 1979. Coleção Práticas do teatro - Tradução de José Ronaldo Faleiro .

COPEAU, Jacques. Início da Escola do Vieux Colombier, in Registros III. Os Registros do Vieux Colombier (Velho Pombal). Textos coletados e estabelecidos por Marie-Hélène Dasté e Suzanne Maistre Saint-Denis. Notas de Norman Paul. Paris: Gallimard, 1979. Tradução de José Ronaldo Faleiro.

COPEAU, Jacques. O Teatro do Vieux Colombier (Velho Pombal), in Registros I. Textos coletados e estabelecidos por Marie-Hélène Dasté e Suzanne Maistre Saint-Denis. Notas de Claude Sicard. Paris: Gallimard, 1974. Tradução de José Ronaldo Faleiro.

JOMARON, Jaqueline. Jacques Copeau - Le Tréteau nu [O tablado nu], in O Teatro na França - da Idade Média aos nossos dias. Paris: Armand Colin, 1992. Tradução de José Ronaldo Faleiro.

MOSTAÇO, Edélcio. Aspectos da Iluminação, In Folhetin n ${ }^{\circ}$ 25; Teatro do Pequeno Gesto; janeiro a junho de 2007.

PONTES, Eloisa. LouIs Jouvet e o nascimento da crítica e do teatro brasileiro moderno. XXIV Encontro anual da AMPOCS; Grupo temático n ${ }^{\circ}$ 10. Pensamento Social no Brasil. Outubro, 2000 .

PRENAFETA, Beato. DIAS, Jamil. PIEDADE, Milton. Iluminação Cênica - Fragmentos da História. São Paulo: ABrIC, 2005.

ROUBINE, Jean-Jacques. A Linguagem da Encenação Teatral.Tradução de Yan Michalski $2^{\mathrm{a}}$ edição. Rio de Janeiro: Editora Jorge Zahar, 1998. 